\title{
Os processos formativos da licenciatura em educação do campo: novos e outros saberes e fazeres evidenciados pelos/nos cadernos da realidade
}

The formative processes of the degree in field education: new and other knowledge and doing evidenced by/in the notebooks of reality Janinha Gerke Alessandro da Silva Guimarães Miriã Lúcia Luiz

\begin{abstract}
Resumo: O texto reflete a produção dos saberes dos estudantes do curso de Licenciatura em Educação do Campo no que tange aos seus processos formativos, tomando como fonte os Cadernos da Realidade, uma mediação pedagógica fundamental no processo metodológico da Pedagogia da Alternância. Baseia-se no pensamento de Marc Bloch (2001), Carlo Ginzburg (2002, 2007a, 2007b) para operar a partir da multiplicidade de fontes e da necessidade de interrogação das mesmas para a produção da narrativa histórica, que se constitui por meio do mergulho nas fontes estudadas de forma, ao mesmo tempo rigorosa e flexível. Nessa perspectiva, trata-se de buscar nos Cadernos da Realidade indícios e sinais que possibilitam a compreensão dos processos formativos dos estudantes do curso de Licenciatura em Educação do Campo, da Universidade Federal do Espírito Santo. Os resultados apontam que os Cadernos da Realidade, tomados numa leitura questionadora e interrogativa, mostramse como portas de entrada - ou por vezes, frestas ou fendas - que permitem refletir sobre as inúmeras experiências históricas, sociais e culturais ligadas as diferentes realidades dos sujeitos do campo e que são imprescindíveis de serem exploradas quando pensadas na construção de uma educação que dialogue com tais experiências. Palavras-chave: Educação do campo. Pedagogia da Alternância. Caderno da Realidade. Formação Docente.
\end{abstract}

Abstract: The text reflects the knowledge production of students from the undergraduate course in Rural Education, concerning their formative processes, taking as a source the Notebooks of Reality, a fundamental pedagogical mediation in the methodological process of the Alternation Pedagogy. It is based on the thought of Marc Bloch (2001), Carlo Ginzburg $(2002,2007 a, 2007 b)$ to operate from the multiplicity of sources and the need to interrogate them for the production of the historical narrative, which is constituted by diving into the sources studied in a simultaneously rigorous and flexible way. In this perspective, it is a question of searching the Notebooks of Reality for clues and signs that enable the understanding of the formative processes of undergraduate students in Rural Education at the Federal University of Espírito Santo. The results indicate that the Notebooks of Reality, taken in a questioning and interrogative reading, are shown as entrance doors - or sometimes, gaps or cracks - that allow us to reflect on the innumerable historical, social and cultural experiences linked to the different realities of the rural subjects and that are indispensable to be explored when thought of in the construction of education that dialogues with such experiences.

Keywords: Rural education. Alternation Pedagogy. Reality Notebook. Teacher Training.

\section{Introdução}


O texto apresenta as principais reflexões produzidas a partir do projeto de pesquisa intitulado Os processos formativos dos estudantes do curso de Licenciatura em Educação do Campo/Ufes: um olhar com e pelos Cadernos da Realidade, desenvolvido na Universidade Federal do Espírito Santo, campus Goiabeiras, no âmbito da Licenciatura em Educação do Campo (LedoC/Ufes). Trata-se de um trabalho investigativo construído nos últimos quatro anos a partir de provocações acerca dos usos dos Cadernos da Realidade, compreendendoos como artefatos que figuram como propulsores da aprendizagem profissional docente, sendo ainda uma mediação pedagógica imprescindível na Alternância.

Situa-se no âmbito da LedoC/Ufes, nos cursos de Ciências Humanas e Sociais; e Linguagem, criados em 2014 com o objetivo de atenderem a uma demanda formativa de professores-educadores do campo para atuarem nos anos finais do Ensino Fundamental, Ensino Médio, Educação de Jovens e Adultos, e na gestão. Os cursos são ofertados por área do conhecimento, buscando uma integração disciplinar e uma organicidade pautada nas relações de complementariedade entre os campos do conhecimento e os territórios formativos, organizados nos espaços e tempos da universidade e da comunidade.

Como perspectiva teórico-metodológica, a pesquisa ancora-se no pensamento de Marc Bloch (2001) e Carlo Ginzburg (2002, 2007a, 2007b), buscando na multiplicidade de fontes e na necessidade de interrogação das mesmas a produção da narrativa histórica, que se constitui por meio do mergulho nas fontes estudadas de forma, ao mesmo tempo rigorosa e flexível.

Desta forma, trazemos nas linhas que compõem este texto os objetivos do projeto investigativo, sua perspectiva teórico-metodológica e os percursos produzidos. Compartilhamos também os principais resultados e as reflexões oriundas da pesquisa, considerados como significativos no pensar e fazer da docência na LedoC/Ufes junto à formação dos sujeitos professores-educadores do campo. Especificamente, buscamos analisar os contornos deste projeto a partir de dois eixos principais: a) refletir a respeito da importância dos Cadernos da Realidade para os processos formativos dos estudantes da LedoC/Ufes; e b) 
analisar temas, práticas e sujeitos visibilizados nos/pelos Cadernos da Realidade dos estudantes do curso.

\section{Os processos formativos dos estudantes do curso de Licenciatura em Educação do Campo/Ufes: um olhar com e pelos Cadernos da Realidade}

Este projeto de pesquisa nasceu da inquietude acerca dos usos do Caderno da Realidade, mediação da Pedagogia da Alternância, na LedoC/Ufes, com o objetivo precípuo de investigar a produção dos saberes dos estudantes do referido curso no que tange aos seus processos formativos, tomando como fonte os Cadernos da Realidade em interlocuções teóricas com o pensamento de Bloch (2001) e Ginzburg (2002, 2007a, 2007b).

Para além disso, a pesquisa buscou: a) analisar os Cadernos da Realidade em seus contextos de produção, compreendendo a percepção e usos dos estudantes a respeito desses artefatos culturais para a formação docente; b) interrogar os registros das produções dos Cadernos da Realidade, considerando a perspectiva do diálogo entre os múltiplos saberes mobilizados nos diferentes espaçostempos educativos (Tempo-Universidade-TempoComunidade), bem como suas articulações com as problemáticas das comunidades em que estão inseridos; c) problematizar de que modo os usos que os alunos fazem dos Cadernos expressam os Currículos pensadospraticados (OLIVEIRA, 2003) na LedoC/Ufes; d) compreender as intervenções promovidas pelos estudantes nas comunidades em que atuam, partindo de uma perspectiva dialógica com base nos registros dos Cadernos da Realidade; e) analisar os enunciados concretos produzidos nos/pelos Cadernos da Realidade, trabalhando a linguagem em sua concretude real: os discursos, as vozes e as contradições sociais que deles ecoam, no sentido de perceber os entrecruzamentos entre a vida campesina, sua cultura, artes de fazer, trabalho e formação docente.

Desta forma, considerando o processo de produção da LedoC/Ufes, pretendeu-se contribuir com problematizações sobre o Caderno da Realidade, que constitui um dos artefatos culturais da Pedagogia da Alternância, adotado no curso. 
Mas o que é, então, o Caderno da Realidade? Trata-se de uma mediação da Pedagogia da Alternância, nascido na França, na experiência das Maisons Familiales Rurales, com o propósito de reunir as principais atividades produzidas pelos estudantes no período de estadia na propriedade familiar, em especial as pesquisas desenvolvidas a partir do Plano de Estudos:

[...] o cahier d' exploitation familiale, traduzido como Caderno de Propriedade, resultou de um desenvolvimento gradual até atingir sua forma definitiva. Inicialmente, denominado La monographie de village, ele consistia no exercício pelos jovens de observação e coleção das informações referentes à história da localidade, envolvendo os membros da comunidade na realização da pesquisa. (ROCHA, 2003, p. 89)

No Brasil, o Caderno da Propriedade, após análise dos contextos formativos dos estudantes capixabas e das leituras freirianas pelos monitores Sérgio Zamberlan e Mário Zulianni, passa a ser entendido e denominado de Caderno da Realidade, pois houve uma compreensão de que esta é muito mais ampla do que a propriedade familiar (ZAMBERLAN, 2019). Para além, uma parte significativa de estudantes das Escolas Família Agrícola não possuíam propriedade agrícola, não fazendo assim sentido seu conceito original em meio aos filhos de meeiros, diaristas, assalariados rurais (ZAMBERLAN, 2019).

O Caderno da Realidade constitui-se no caderno da vida do estudante, no qual ele registra suas reflexões acerca de sua realidade. Trata-se de uma sistematização das principais questões discutidas a partir do Plano de Estudo. Nele são registrados a síntese individual, síntese geral, uma ilustração sobre o Plano de Estudo e a Folha de Observação. O Caderno da Realidade possibilita ao educando um olhar em retrocesso de sua caminhada no processo formativo da Pedagogia da Alternância (MEPES, s.d.).

À vista disso, o Caderno da Realidade foi assumido pelos sujeitos em formação da Pedagogia da Alternância como um arcabouço prático e teórico das produções investigativas acerca dos contextos de vida e trabalho no campo. Ele acolhe os trabalhos de análise da realidade, com atividades de produção escrita individual e coletiva, ilustrações, cartografias e questionários que tensionam situações-problema vividas. 
$\mathrm{Na}$ LedoC/Ufes, o Caderno da Realidade passa a ser adotado como mediação pedagógica desde o início do curso (2014), cunhando processualmente aprendizagens no coletivo docente e discente. Como nova proposição no ensino superior, fez-se necessário empreender uma busca acerca de seus usos, partindo do pressuposto de que sua existência se revela potente nos processos formativos.

Outrossim, compreendemos que os Cadernos da Realidade, em articulação com as narrativas dos sujeitos que os produziram, constituem-se em significativas mediações de problematização da formação docente e dos movimentos inventivos curriculares, como também em fontes para a produção da narrativa histórica acerca desses processos formativos e sua constituição de sentidos para os estudantes.

São estas, portanto, as principais reflexões trazidas nas linhas que seguem, compreendidas por nós não apenas como resultados do trabalho investigativo, mas como novos usos dessa mediação pedagógica na formação por Alternância na LedoC/Ufes, entendida como conquista dos campesinos na luta pela construção de uma outra escola, como afirma Arroyo (2019, p. 79):

Os movimentos sociais do campo lutam por escola, por outra escola diferente da escola rural tradicional das primeiras letras. Lutam pelo direito dos povos dos campos ao conhecimento de que também são produtores. Mas proclamam lutar por uma escola que seja mais do que escola. Que seja tempo-espaço do direto à educação, à formação humana plena. Logo, lutam pela formação de profissionais que sejam mais do que ensinantes, que sejam educadoras, educadores.

É em meio a este contexto de produção de uma outra escola, pela via de uma outra formação de professores-educadores do campo, permeada pela diversidade de sujeitos advindos das diferentes experiências da educação do campo, que se dá o trabalho com os Cadernos da Realidade e, consequentemente, este estudo.

\section{Percurso Metodológico da Pesquisa: Tecendo saberes e fazeres evidenciados nos/pelos Caderno da Realidade}

Nas reflexões aqui ensejadas, em que privilegiamos os Cadernos da Realidade, utilizamos como aporte teórico-metodológico os pensamentos de 
Marc Bloch (2001) e Carlo Ginzburg (2002, 2007a, 2007b) a respeito da multiplicidade de fontes e da necessidade de interrogação delas para a produção da narrativa histórica, que se constitui por meio do mergulho nas fontes estudadas de forma, ao mesmo tempo rigorosa e flexível.

A compreensão de fontes históricas compartilhada pelos autores referidos interessa-nos especialmente, pois ao abrigarem nessa noção tudo o que homens e mulheres produzem ao longo do tempo, a ideia de se trabalhar com aquilo que é vivo ganha notoriedade nessa perspectiva teórico-metodológica. Nesse sentido, Bloch (2001, p. 54) situa os homens [e mulheres] como objetos da História. É o que lemos em suas palavras:

Por trás dos grandes vestígios sensíveis da paisagem, [os artefatos ou as máquinas,] por trás dos escritos aparentemente mais insípidos e as instituições aparentemente mais desligadas daqueles que as criaram, são os homens [e mulheres] que a história quer capturar. [...]. O bom historiador se parece que 0 ogro da lenda. Onde fareja carne humana, sabe que ali está a sua caça.

Com essa predileção pelo que é vivo, esse autor, assim como Ginzburg, nos alerta para dois elementos essenciais no tratamento da fonte. O primeiro refere-se ao processo de produção do documento, que, longe de ser neutro, carrega consigo toda uma intencionalidade. Porém, e longe de ser desprezível, também deve ser lido em contraposição às intenções de quem o produziu, ou, se preferir, a contrapelo (termo utilizado por Ginzburg com inspiração no pensamento de Walter Benjamin). Por isso, torna-se necessário compreender que todo texto inclui elementos incontroláveis, como explicita Ginzburg (2002, p. 43): "[...] Só dessa maneira será possível levar em conta tanto as relações de força quanto aquilo que é irredutível a elas". O outro aspecto a se considerar é o fato de as fontes não "falarem" por si só, a não ser quando interrogadas. A esse respeito Ginzburg se opõe à compreensão de que as fontes, se dignas de fé, oferecem um acesso imediato à realidade. Pelo contrário, para ele:

As fontes não são nem janelas escancaradas, como acreditam os positivistas, nem muros que obstruem a visão, como pensam os céticos: no máximo poderíamos comparar a espelhos deformantes. A análise da distorção específica de qualquer fonte implica já um elemento construtivo [...]. Mas a construção [...] não é incompatível com a prova; a projeção do desejo, sem o 
qual não há pesquisa, não é incompatível com os desmentidos infligidos pela realidade. $O$ conhecimento (mesmo 0 conhecimento histórico) é possível. (GINZBURG, 2002, p. 4445)

É com isso em mente que lançamos nossos olhares para o projeto que assumiu como fonte os Cadernos da Realidade e, especificamente, para esses registros, pois, assim como Ginzburg (2007b), nos interessamos igualmente tanto pelas perguntas, como pelas respostas - por vezes as primeiras até nos parecem mais significativas, por serem mais dificilmente rechaçadas. Ao analisarmos o que pode ser lido como resultados, portanto, como respostas às questões inicialmente postas à investigação, intencionamos compreender outros e novos saberes e fazeres produzidos pelos estudantes da LedoC/Ufes mediados pelos Cadernos da Realidade, na certeza de que outras questões eloquentes a esses processos formativos poderão emergir.

Em termos procedimentais, ao longo do desenvolvimento do projeto, acessamos, por livre adesão dos estudantes das duas habilitações (Ciências Humanas e Linguagens), 38 Cadernos da Realidade entre 2016 e 2020, os quais buscamos ler minuciosamente, na busca de "fazermos falar" tanto o que está visível no texto como aquilo que está fora do texto, abrigando-se entre as suas dobras (GINZBURG, 2002).

Nesse movimento, buscamos realizar ações diversas, como encontros mensais junto aos integrantes do projeto e leituras semanais selecionadas pelo grupo, visando traçar estratégias e metodologias para os diálogos com os cadernos, que se constituíram momentos fecundos de ação-reflexão-ação acerca dos processos formativos proporcionados pelo curso, bem como sobre as possibilidades de intervenção nas comunidades.

Produziu-se um banco de dados a partir da digitalização dos Cadernos da Realidade dos estudantes do curso e das análises produzidas pelos integrantes do grupo e das atividades realizadas pelos acadêmicos, o que por sua vez evidenciou a riqueza das produções em curso, como também as especificidades e singularidades de um trabalho que se dá nos entrelugares da individualidade e coletividade. Como parte dessas produções, destacamos artigos produzidos, submetidos e publicados em periódicos da área: Os processos formativos dos 
estudantes da LEC/UFES ${ }^{1}$ : um olhar com/pelos Cadernos da Realidade (2017); Trajetórias de mulheres camponesas no Espírito Santo: permanências e descontinuidades (2018); A constituição da Escola Estadual de Ensino Fundamental e Médio Pastor Antônio Nunes de Carvalho no município de Alto Rio Novo/ES (1986-2017) (2020) e Memórias e narrativas dos estudantes da educação do campo mediadas pelo caderno da realidade (Em avaliação).

Não obstante, foram realizados encontros quinzenais e/ou mensais para estudo e aprofundamento do referencial teórico-metodológico e para leitura e análise dos Cadernos da Realidade. Trimestralmente, realizamos encontros com os estudantes do curso na Universidade e em suas comunidades. O deslocar docente até a comunidade foi e é uma ação imprescindível na compreensão em contexto do uso dos Cadernos da Realidade como mediação das relações teórico/práticas, entre Tempo-Comunidade e Tempo-Universidade.

As Rodas de Conversa constituíram-se igualmente em ações profícuas no desenrolar da pesquisa. Realizadas na Universidade e Comunidade, destacamse os diálogos com Sr. Manoel Loreno, cineasta "artesanal" da cidade de Mantenópolis-ES, especialmente com os estudantes da Licenciatura em Educação do Campo, potencializando a discussão acerca dos saberes dos sujeitos das comunidades, suas produções culturais e divulgação desses saberes pela via midiática, e com uma pesquisadora da Educação do Campo sobre os Cadernos da Realidade nesse contexto.

Analogamente, se deram as Rodas de Conversa na Escola Família Agrícola (EFA) de Olivânia, localizada em Anchieta e reconhecida como a primeira EFA da América latina. As rodas, organizadas em dois momentos, destinaram-se ao conhecimento-reconhecimento do espaço e dos modos como se produzem as práticas na/da instituição nos Tempos Escola e Comunidade. $O$ movimento de ir ao encontro dos usos do Caderno da Realidade na escola provocou-nos acerca das especificidades desse trabalho no âmbito da Educação Básica e do Ensino Superior.

\footnotetext{
${ }^{1}$ No contexto de escrita do artigo o uso da expressão LEC/UFES era comum entre os professores e os estudantes do curso. O primeiro contato com a sigla LedoC ocorreu no $5^{\circ}$ Seminário Nacional de Licenciaturas em Educação do Campo Universidade Federal da Fronteira Sul (UFFS) - Campus Laranjeiras do Sul, em 2015 e, gradualmente, essa denominação (LedoC/Ufes) para a ser adotada no curso e na Universidade.
} 
Em meio a este cenário, produziu-se também, junto aos estudantes finalistas do $8^{\circ}$ período de Ciências Humanas, no semestre de 2019/1, uma interlocução de todas as suas produções no âmbito do Caderno da Realidade construídas no diálogo com os contextos campesinos das comunidades. Este trabalho, vivido ao longo do referido semestre por meio de uma reflexão interdisciplinar, buscou aglutinar e sintetizar ideias e resultados de pesquisas produzidas a partir de diversas disciplinas do curso desde o seu início. Esse movimento favoreceu uma reflexão conjunta sobre os processos formativos produzidos no âmbito da Ledoc/Ufes, culminando em uma apresentação na qual os estudantes trouxeram imagens e depoimentos que refletissem sua passagem pelo curso e também nos levaram a perceber o Caderno da Realidade como mediação que dialoga com a história do estudante no curso. Nesse sentido, a exposição figurou como espaço e tempo de visibilidade dos saberes e fazeres, advindos das realidades campesinas, dialogados com o conhecimento curricular e sistematizados nos Cadernos da Realidade.

As ações investigativas nos conduziram também a realizar uma análise documental sobre os Cadernos da Realidade no Centro de Formação e Reflexão do Movimento de Educação Promocional do Espírito Santo (MEPES), localizado em Piúma. Nele foram encontrados documentos históricos que revelam a processualidade da construção teórico-prática da Alternância no Brasil e, como artefato desta, a caminhada das construções sobre o Caderno da Realidade. Trata-se de documentos significativos na compreensão histórica da Pedagogia da Alternância e da Educação do Campo no território brasileiro.

Outro momento significativo no percurso investigativo se deu em 2019 junto ao professor-monitor Sérgio Zamberlan, por meio de um diálogo semiestruturado, nos possibilitando uma apropriação histórica das idealizações sobre o Caderno da Realidade e seu potencial formativo. A escuta das reflexões acerca dos desafios encontrados no início dos trabalhos das Escolas Família Agrícola no Espírito Santo e a construção de um arcabouço didático-pedagógico para sustentação da Pedagogia da Alternância demandaram a necessidade da criação de um Centro de Formação e Reflexão dos docentes da Alternância. Este espaço foi e ainda é lócus de construções pedagógicas imprescindíveis na 
educação do campo. Foi nesse espaço de reflexão que nasceu o Caderno da Realidade brasileiro.

Portanto, rememorar e registrar as ações nesse momento nos oportuniza olhar a trajetória investigativa, reconhecer os sujeitos envolvidos e compartilhar as reflexões produzidas, permitindo assim trazer à baila os principais contributos da pesquisa para a Licenciatura em Educação do Campo.

\section{A produção de novos e outros saberes e fazeres da formação docente do campo: olhares e leituras dos/pelos Cadernos da Realidade}

Como reflexão do percurso produzido, traduzido ainda como resultados alcançados, compreendemos que os Cadernos da Realidade apontam potencialidades que permitem a ampliação do olhar para os múltiplos processos formativos e de invenções curriculares acerca do caminho percorrido ao longo da formação. Evidenciam-se os saberes e fazeres produzidos pelos estudantes da Licenciatura em Educação do Campo em consonância com as questões de vida do/no campo.

A análise documental, realizada no Centro de Formação e Reflexão do Movimento de Educação Promocional do Espirito Santo, trouxe aos nossos estudos as marcas históricas da constituição dessa mediação pedagógica. São documentos que refletem usos diversos no decorrer da história, migrando de apropriações mais pragmáticas das pesquisas realizadas em campo para saberes e fazeres que tornam o Caderno da Realidade como mediação das relações de reciprocidade dos tempos formativos e da integração teoria e prática.

Ao estabelecermos distinções em relação aos contornos assumidos pelos Cadernos nas Escolas Família Agrícola e na Licenciatura em Educação do Campo, depreendemos que no âmbito da formação docente este artefato constitui-se, para além da sistematização das pesquisas a partir dos Planos de Estudos, em lócus de experiências individuais e coletivas. Construiu-se nesse processo um entendimento dos Cadernos como fomentadores do pensar a existência humana no território campesino. Nessa perspectiva, O Caderno da Realidade na formação docente do campo assume dimensões que visibilizam os saberes e fazeres dos estudantes - povos campesinos - reconhecendo-os como novos e outros modos de conhecer/viver/existir e, ainda: 
[...] os CR constituem-se em importante elemento para pensarmos a formação dos estudantes, sobretudo por se materializarem como produção autoral, registros de subjetividades, movimentos, emoções, percepções e reflexões dos estudantes. São, portanto, fontes para a escrita da história do curso, das comunidades e de cada sujeito inserido no processo [...]. (LUIZ; ALCÂNTARA, 2018, p. 20) ${ }^{2}$

Tal compreensão problematiza os modos convencionais da formação docente pautados por uma racionalidade objetiva e de apagamento das singularidades. O que entra em cena com o trabalho a partir da apropriação do Caderno da Realidade na Formação Docente do Campo é a instituição não apenas de uma nova mediação pedagógica e/ou um novo elemento didático, mas a possibilidade de, por meio deste, trazer para o âmbito da universidade as subjetividades, os saberes e fazeres dos povos campesinos, suas memórias, experiências e lutas. Ao ocuparem as páginas do Caderno da Realidade, tais saberes e fazeres ganham vida nas discussões da sala de aula, adentram os currículos da universidade, quebram paradigmas e constroem lógicas mais fecundas para os estudantes.

\section{Temas, práticas e sujeitos visibilizados nos/pelos Cadernos da Realidade dos estudantes da Licenciatura em Educação do Campo}

No âmbito do projeto analisado, cada página que compõe os Cadernos da Realidade revelou-nos confidências, marcas de vida, de percursos, de certezas e incertezas. Pudemos experimentar, ao menos por alguns instantes, a alegria da entrada em uma universidade pública - que para tantos parecia um sonho inalcançável -, as surpresas, as compreensões e os estranhamentos no primeiro contato com os professores, com as leituras e com o universo da pesquisa. Ao folhearmos aquelas páginas, vivenciamos encontros, conhecemos e reconhecemos sujeitos e contextos, com suas lutas cotidianas comuns e distintas. É assim que as histórias se constituem, por esses fios na composição da tapeçaria (GINZBURG, 2007a). É nesse movimento de aproximações das vivências na universidade com seus contextos de vida, de incentivo aos registros de cada experiência, das leituras e dos diálogos que os processos formativos

\footnotetext{
${ }^{2}$ No texto original as autoras optaram por usar a sigla CR para designar os Cadernos da Realidade.
} 
dos estudantes da Licenciatura em Educação do Campo se constituíram. Desses registros, quais temas foram visibilizados? Quais sujeitos foram privilegiados? Quais práticas esses sujeitos nos permitiram ler ao produzirem suas narrativas em seus Cadernos da Realidade?

Como problematização a essas interrogações, alguns registros dos cadernos nos chamaram a atenção, sobretudo, por centralizarem temas, sujeitos e práticas historicamente negligenciadas no que se referem a pesquisas e estudos produzidos academicamente no campo da educação. Dentre esses enfoques, destacamos: a) as mulheres do campo e suas trajetórias de vida, de escolarização e na universidade; b) a constituição de instituições escolares, movimentos e instâncias organizativas do campo e práticas ensejadas em instituições que ofertam a Educação do Campo; e c) manifestações culturais dos sujeitos do campo e os modos de invenção e significação da vida.

Os temas e problemáticas que aqui visibilizamos se materializaram nos Trabalhos de Conclusão de Curso dos estudantes que, ao serem elaborados durante as suas trajetórias de formação no curso, sustentaram-se prioritariamente naquilo que, de forma descritiva ou analítica, foi registrado em seus Cadernos da Realidade, já que para Gerke de Jesus (2007, p. 55),

[...] eles possibilitam aos estudantes resgatar e sistematizar sua história de vida, retomando questões discutidas em outros momentos e, como consequência, amadurecer intelectualmente pelo exercício da pesquisa, da reflexão, do registro e da elaboração de síntese.

As escolhas dos registros de cada estudante estiveram intimamente relacionadas aos seus olhares, às suas vivências e aos modos como interpretavam seus contextos de vida a partir das apropriações teóricas e metodológicas que fizeram ao longo do curso, isso porque, de acordo com Bloch (2001, p. 66)

[...] conscientemente ou não, [são] sempre as nossas escolhas cotidianas que, para nuançá-las onde se deve, atribuímos matizes novos, em última análise os elementos, que nos servem para reconstituir o passado [...]. 
Nesse caminho, Oliveira (2018), ao justificar a escolha do tema de seu Trabalho de Conclusão de Curso, destaca a sua aproximação com discussões produzidas em diferentes espaços coletivos a respeito da mulher camponesa:

Sou militante do Movimento dos Pequenos Agricultores (MPA),
espaço onde a temática mulher é bastante presente,
principalmente, no que tange ao espaço rural. Participei de
alguns eventos nos âmbitos municipal, estadual e, até nacional.
Sabemos que as mulheres nunca apareciam como destaque na
história e o MPA sempre busca trazer nomes de mulheres que
foram importante nas lutas e conquistas. (OLIVEIRA, 2018, p. 7 ,
grifo a autora)

A partir disso, a estudante buscou compreender a trajetória de mulheres camponesas de Domingos Martins-ES, no período de 1930 a 2017³, investigando os modos como viveram/vivem e perceberam/percebem sua infância, trajetórias pessoais, processos de inserção como trabalhadoras e partícipes dos espaços sociais de suas comunidades, bem como os sentidos que a escolarização assume ao longo de suas vidas. Oliveira (2018) entende essas mulheres como lutadoras e guerreiras, porém, portadoras de muito sofrimento pela herança da sociedade patriarcal, muito marcante no município. A estudante identificou como desdobramento dessa reflexão, questões relativas ao machismo, à submissão e exclusão feminina, que estão muito enraizadas na nossa sociedade. Atitudes sofridas e cometidas no dia a dia em relação a essas mulheres.

As conclusões deste estudo indicaram permanências e descontinuidades nas trajetórias das mulheres capixabas no período investigado. Como permanências, Oliveira (2018) destaca a mulher ocupando os espaços domésticos, sobretudo, exercendo atividades hercúleas, desprovidas de valor econômico. O modelo patriarcal de família/sociedade se presentifica nas narrativas e nos registros de mulheres de diferentes tempos geracionais. Emanaram das narrativas das mulheres indícios de descontinuidades, tais como: a inserção ainda criança no processo de escolarização, o protagonismo das

\footnotetext{
${ }^{3}$ A pesquisa contou com narrativas de quatro mulheres com as seguintes idades: $92,85,81 \mathrm{e}$ 21 anos.
} 
mulheres no âmbito doméstico, comunitário e nos espaços mais amplos da sociedade, como a Universidade.

O estudo desenvolvido por Novo e Guilherme (2018) também se insere na perspectiva de problematização e visibilização das mulheres do campo, ao promover um diálogo com as trajetórias de mulheres, estudantes do curso da LedoC Ufes/Goiabeiras. Partindo de uma escuta atenta, crítica e analítica, esta pesquisa de conclusão de curso procurou entender quais desafios e dificuldades elas enfrentam e investigar o impacto que sua entrada na universidade vem ocasionando em suas trajetórias de vida, bem como nos diversos espaços sociais em que estão inseridas, destacando aqui os círculos comunitários e familiar.

A pesquisa evidenciou que as mulheres trazem um discurso acerca da questão dos seus direitos no sentido mais amplo do termo e (re)afirmam como uma de suas lutas a busca por uma maior igualdade de gênero. Elas não apenas narram ou descrevem a desigualdade por elas vivida - que é extremamente marcante nos depoimentos -, mas também questionam e problematizam o lugar da mulher nos diferentes espaços sociais, demonstrando que são sujeitas políticas, conscientes de seu papel no mundo. Reiteram, portanto, a importância que essa reflexão assume na sua formação enquanto futuras educadoras, no sentido de promover tais discussões em suas comunidades e espaços vivenciais.

Buscando visibilizar sujeitos e instituições educativas e seus processos de constituição, considerando as peculiaridades das comunidades e demandas sociais que implicaram em sua criação e consolidação, Jadejiski (2018) investigou a constituição da Escola Estadual de Ensino Fundamental e Médio "Pastor Antônio Nunes de Carvalho" (1986-2017), localizada no município de Alto Rio Novo/ES, buscando compreender a sua atuação frente aos desafios da evasão e repetência junto ao público local no âmbito do Ensino Médio.

Segundo esse estudante, a escolha dessa temática de estudo se deu a partir de sua inquietação profissional enquanto professor de História e Geografia da referida escola. Os resultados da pesquisa demonstraram que a reprovação e o abandono escolar afetam diretamente a vida dos estudantes, pois muitos 
perdem o estímulo para estudar e não regressam para a escola. Os sujeitos questionados percebem a escola como um espaço para desenvolver a criticidade dos estudantes e para prepará-los para a vida em sociedade. No contexto investigado foi evidenciado que a escola desenvolve ações para modificar o quadro de reprovação e evasão, tais como incentivo aos estudantes em prosseguir com os estudos, trabalho com projetos e diversas estratégias de recuperação.

A partir desses movimentos de pesquisa, entendemos que as inquietações iniciais se transformaram em investigações, assumindo contornos definidos e determinantes para a formação desses estudantes. Isso indicia a estreita relação entre os saberes produzidos e mobilizados no âmbito do curso com os contextos de vida e de trabalho dos estudantes, especialmente potencializados pela via dos Cadernos da Realidade. É o que identificamos também na produção de Boskeviski e Coco (2018); ao investigarem os processos de constituição do Comitê Municipal de Educação do Campo (COMEC), situado em São Gabriel da Palha, além do fato de residirem no município e de acompanharem as ações do comitê, os estudantes delineiam os contornos do tema a partir de interlocuções iniciadas desde os primeiros períodos do curso de Licenciatura em Educação do Campo. Em suas palavras: "[...] nas experiências vivenciadas nos diálogos entre o Tempo-Universidade e o Tempo-Comunidade, pudemos nos aproximar das entidades, movimentos e sujeitos que se dedicam à luta pela Educação do Campo" (BOSKEVISKI, COGO, 2018, p. 5).

Desse modo, os estudantes investigaram as ações que propiciaram a criação do Comitê; analisaram historicamente o papel dessa instituição no município e os desdobramentos das ações empreendidas pelo mesmo nas escolas da localidade. Por meio da análise dos documentos - atas de reuniões e de assembleias, registros de desafio do COMEC, regimento interno da entidade e depoimento de um representante da comunidade -, os pesquisadores concluíram que a criação do COMEC justifica-se pela defesa das necessidades das pessoas que residem no campo e as reivindicações das escolas municipais e estaduais do campo situadas no município. Além das considerações, o estudo 
apontou também desafios, notadamente, a necessidade de participação efetiva no Conselho Municipal de Educação e a ameaça constante de fechamento das escolas do campo. Como conquistas registradas pela entidade destacaram-se a reabertura de escolas do campo e abertura e o funcionamento de uma instituição de Educação Infantil no contexto campesino.

Nos estudos aqui privilegiados foram de crucial importância o lugar e o tratamento das fontes, compreendidas nessa pesquisa, como todo e qualquer vestígio deixado por homens e mulheres no tempo $(\mathrm{BLOCH}, 2001)$, isso porque nenhuma narrativa seria possível sem os fios e os rastros encontrados nos percursos de pesquisa. É nesse sentido que ganham ainda mais centralidade os Cadernos da Realidade, pois, para além de uma nova mediação pedagógica, constituem-se em fontes para refletirmos a respeito dos processos formativos dos estudantes da Licenciatura em Educação do Campo. Esse movimento nos possibilitou uma aproximação dos contextos, sujeitos e problemáticas que envolvem o campo e suas singularidades.

Assumindo o espaço de uma escola do campo como lócus de sua pesquisa e reflexão, Ferreira, Silva e Raach (2019) buscam refletir, a partir de entrevistas com professores e estudantes de uma instituição situada no Município de Domingos Martins, a respeito das experiências daquele tempoespaço educativo com o uso do Caderno da Realidade. O estudo buscou compreender suas relações com a concretização da Pedagogia da Alternância e sua importância para o reconhecimento dos saberes e da cultura camponesa vividos pelas comunidades atendidas pela escola analisada.

Com aporte teórico-epistemológico na pedagogia dialógica Freiriana, o estudo justifica-se pela importância de se entender o Caderno da Realidade enquanto espaço mediador de diferentes experiências formativas e que, sobretudo, ele pode auxiliar, de vários modos, na construção coletiva de uma educação autentica que valorize a cultura camponesa e os sujeitos do campo e também fortaleça processos e laços identitários. Unindo o saber científico e as vivências práticas dos estudantes, os autores evidenciam que o Caderno da Realidade é um espaço importante para um dos grandes objetivos da Pedagogia 
da Alternância, que é assumir diferentes espaços vivenciais/laborais em espaços formativos. Desta forma, concluiu-se que:

Mais que um registro da vida escolar, o caderno da realidade traz em suas folhas experiências de uma educação que ultrapassa as paredes da escola, pois compreende que há outros espaços educativos que são igualmente importantes para mediar o aprendizado do estudante. (FERREIRA, SILVA, $\mathrm{RAACH}, 2019$, p. 42)

Em meio aos temas e sujeitos visibilizados por esses registros, encontramos o Grupo de Caxambu Andorinha, localizado no município de Jerônimo Monteiro/ES. Ao tematizarem esse elemento da cultura capixaba, Azaria e Cerqueira (2019) objetivaram compreender a origem, os processos de disseminação e as apropriações culturais no município, promovendo a valorização e reconhecimento desse patrimônio cultural.

Este estudo apontou elementos importantes para pensarmos as questões culturais do/no Espírito Santo e, especificamente, das/nas comunidades situadas no campo, dentre as quais, elencamos: a) o fato do Caxambu não ser reconhecido como um patrimônio cultural jeromense, que se evidenciou especialmente na limitada participação dos moradores do entorno do barracão, local onde se realiza essa prática; b) As mudanças pelas quais passou o caxambu jeromense com relação à sua forma de apresentação ligadas ao espaço, ao aprimoramento das técnicas e à incorporação de novas possibilidades criativas e; c) a compreensão do Caxambu para além de uma atividade cultural. Ao longo do tempo este passou a se constituir parte da vida e da memória de seus brincantes, por meio do qual, divulgam o conhecimento sobre a prática, sobre tudo ensinar aos jovens.

Para além dos temas, sujeitos e práticas visibilizados pelos estudantes em suas produções acadêmicas, indissociavelmente subsidiadas pelos registros dos Cadernos da Realidade, consideramos importante entender como esse processo de elaboração, possibilitado pelas inter-relações entre a universidade e a comunidade, impactou na sua formação como educador do campo. Algumas pistas dessa relação podem ser lidas nos estudos. Especialmente, destacamos reflexões como a de Jadejiski (2018, p. 9): 
Essa problemática se relaciona diretamente com a conclusão da Licenciatura em Educação do Campo, já que em diversos momentos formativos refletimos sobre as condições de acesso e permanência dos estudantes nas escolas, sobretudo no contexto campesino.

Em Oliveira (2018) também encontramos indícios dessa estreita relação, ao entender que

a inserção da mulher camponesa Martinense no Ensino Superior e, mais especificamente, na Universidade Pública, possibilitando o diálogo entre diferentes culturas e a visibilidade de sua própria atividade como legítima e imprescindível, enseja processos de rupturas não dantes pensados. Logo, a Licenciatura em Educação do Campo/Ufes evidencia essa possibilidade no sentido desse olhar e desse deslocamento e da relevância que Ihe é inerente. (OLIVEIRA, 2018, p. 36)

Ao referir-se aos desafios enfrentados pelo COMEC, em São Gabriel da Palha, Bosquevisk e Cogo (2018) evidenciaram seu entendimento a respeito da atuação dessa entidade no município e, de modo amplo, dos modos de pensar a Educação do Campo. Os estudantes assim se expressaram:

Entendemos que a luta pela Educação do Campo torna-se cada vez mais árdua e complexa e a proposição de outros estudos para ampliar e aprofundar a compreensão dos modos como essa educação tem sido praticada no Espírito Santo se faz necessária. (BOSQUEVISK, COGO, 2018, p. 29)

Esses mesmos estudantes concluem o texto reafirmando que "[...] a identidade cultural dos sujeitos do campo seja respeitada e garantida no espaço em que vivem" (BOSQUEVISK, COGO, 2018, p. 29). É também nessa perspectiva que Azaria e Cerqueira (2019) problematizaram a importância e a necessidade de tratar do Caxambu de Jerônimo Monteiro. Por meio do estudo que se originou de trabalhos realizados no âmbito da disciplina de Antropologia, as autoras buscaram

[...] minimizar o preconceito e a ignorância no que diz respeito às culturas africanas, mostrando sempre o quão importante é a disseminação cultural, com destaque para a perpetuação das práticas culturais, através de proteção e salvaguarda do patrimônio. Busca-se aqui desvelar possibilidades de combate ao racismo além de colaborarmos com o fortalecimento das práticas culturais Afro-capixabas. (AZARIA, CERQUEIRA, 2019, p. 15) 
Por fim, saberes, fazeres, sujeitos e práticas se presentificaram nos Cadernos da Realidade dos estudantes, como pudemos ler na materialidade de suas produções acadêmicas. Não temos dúvidas de que essas incursões teórico/práticas assumem lugar central nos processos formativos dos estudantes. Para além disso, porém, pensamos na abrangência e nos desdobramentos dessas elaborações na atuação dos sujeitos, egressos do curso, em seus contextos de vida e de trabalho, favorecendo a valorização da história e da cultura das comunidades onde se inserem.

\section{Considerações Finais}

Mergulhar nas páginas dos Cadernos da Realidade é um convite para diversas portas que podem se abrir quando as percebemos enquanto temposespaços que capazes de nos levar a constantes interrogações, tais como: quem são os sujeitos que neles registram suas memórias e seus saberes-fazeres? De que modo fazem isso? O que suas experiências educativas e existenciais nos dizem a respeito das culturas e dos modos de vida campesinos? Como pensar a educação do campo enquanto um lugar em pleno movimento de constituição, onde se intercruzam essas diferentes histórias singulares, mas que também encontram pontos de intersecção? A partir de questões como essas, apostamos nas potencialidades que os usos desses cadernos assumem e, metaforicamente, nas "portas que se abrem" também para investigações relativas aos processos formativos dos estudantes do curso de licenciatura em educação do campo.

Neste aspecto, retomando uma ideia central de Ginzburg (2002) que defendemos ao longo deste trabalho, acreditamos que os Cadernos da Realidade constituem-se em fonte histórica, portanto, ao serem interrogadas, indiciam, não necessariamente portas de acesso, mas frestas que nos permitem conjecturar sobre os contornos das inúmeras experiências ligadas aos sujeitos do campo.

Nosso olhar interrogativo e curioso junto aos Cadernos da Realidade tem nos permitido, em alguma medida, des-velar e des-cobrir saberes que nos apontam pistas para refletir os processos formativos na LedoC/Ufes. Assim, nos 
encontros e nos tensionamentos produzidos a partir de experiências singulares e coletivas narradas nestes cadernos, nos deparamos com alguns desafios para a educação do campo, diante, inclusive, das próprias contradições vividas pela sociedade brasileira. Temos, então, questões plurais que perpassam esses cadernos e as mais variadas experiências que assumem a forma de pesquisas acadêmicas, evidenciando, especificamente, temas ligados às desigualdades de gênero e ao cotidiano campesino; questões referentes aos diferentes contextos das escolas de educação básica que atendem aos sujeitos do campo (relações de ensino-aprendizagem, evasão, movimentos que lutam pela escola do campo) e as manifestações culturais dos sujeitos do campo.

Entendemos o projeto aqui analisado, portanto, como uma dessas portas, dentre tantas outras, que podem ser abertas quando assumimos os Cadernos da Realidade enquanto registros vivos que nos convidam a refletir sobre a educação do campo como espaço que deve ser constantemente reinventado, a partir das necessidades e experiências históricas concretas destes sujeitos.

Além da produção acadêmico-científica produzida a partir dos cadernos, também destacamos a importância de oferecer espaços como o que aqui se abre, para que esses registros do Caderno da Realidade possam ser constantemente compartilhados, debatidos e interrogados entre os estudantes nos mais diversos momentos do curso da LedoC, pois como mediação pedagógica, reafirma seu potencial formativo na educação do campo, esta constantemente (re)construída e (re)inventada a partir da história e das trajetórias dos sujeitos que compõem as diferentes realidades do campo em nosso país.

\section{Referências}

AZARIAS, Adriana Aparecida Silva; CERQUEIRA, Eliane Cerqueira. 0 Caxambu no Espírito Santo: contribuições culturais para os povos do campo do município de Jerônimo Monteiro. 2019. 53f. Trabalho de Conclusão de Curso (Licenciatura em Educação do campo), Universidade Federal do Espírito Santo, Vitória, 2019.

ARROYO, Miguel Gonzalez. Outro paradigma pedagógico de formação de educadores do Campo? In: MOLINA, Mônica Castagna; MARTINS, Maria de Fátima Almeida. (Orgs.). Formação de formadores: reflexões sobre as 
experiências da licenciatura em Educação do Campo no Brasil. 1. ed. Belo Horizonte, MG: Autêntica, 2019.

$\mathrm{BLOCH}$, Marc Leopold Benjamin. Apologia da história ou o ofício do historiador. Tradução de André Telles. Rio de Janeiro: Jorge Zahar, 2001.

BOSQUEVISK, Altielys; COGO, Suelaine Silvério. A constituição do Comitê Municipal de Educação do Campo do município de São Gabriel da PalhaES. 2018. 33f. Trabalho de Conclusão de Curso (Licenciatura em Educação do campo), Universidade Federal do Espírito Santo, Vitória, 2018.

FERREIRA, José Mário de, SILVA, Malena da, RAACH, Wellington. A importância do Caderno da Realidade como mediador pedagógico da Pedagogia da Alternância: dialogando com experiências docentes e discentes na EFA São Bento do Chapéu/Domingos Martins. 2019. 43f. Trabalho de Conclusão de Curso (Licenciatura em Educação do campo), Universidade Federal do Espírito Santo, Vitória, 2019.

GERKE DE JESUS, Janinha. Escolas família agrícolas: um projeto específico de educação do campo. In: FOERSTE, Erineu; SCHUTZ-FOERSTE, Gerda Margi; LINS, Andréia Chiara (Org.). Caderno de formação de professores do campo: educação do campo/identidades culturais. Vitória: Ufes, Programa de PósGraduação em Educação, 2007. p. 49-60.

GINZBURG, Carlo. Relações de força: história, retórica, prova. São Paulo: Companhia das Letras, 2002.

GINZBURG, Carlo. Mitos, emblemas, sinais: morfologia e história. 2. ed. São Paulo: Companhia das Letras, 2007a.

GINZBURG, Carlo. O fio e os rastros: verdadeiro, falso, fictício. São Paulo: Companhia das Letras, 2007b.

LUIZ, Miriã Lúcia; ALCÂNTARA, Regina Godinho. Os processos formativos dos estudantes da LEC/Ufes: um olhar com/pelos cadernos da realidade. Revista Brasileira de Educação do Campo, Tocantinópolis, v. 2, n. 1, p. 45-67, 2017.

NOVO, Amanda Guilherme, GUILHERME, Maria da Penha. Gênero, educação e a realidade das mulheres no campo. 2018. 32f. Trabalho de Conclusão de Curso (Licenciatura em Educação do campo), Universidade Federal do Espírito Santo, Vitória, 2018.

OLIVEIRA, Inês B. Currículos praticados: entre a regulação e a emancipação. Rio de Janeiro: DP\&A, 2003.

OLIVEIRA, Deiviani de. A trajetória das mulheres camponesas do município de Domingos Martins-Es. 2018. 41f. Trabalho de Conclusão de Curso (Licenciatura em Educação do campo) - Universidade Federal do Espírito Santo: Vitória, 2018. 
OLIVEIRA, Deiviani de; BRIDI, Luan Eudair; LUIZ, Miriã Lúcia; ALCÂNTARA, Regina Godinho. Trajetórias de mulheres camponesas no Espírito Santo: permanências e descontinuidades. Revista Brasileira de Educação do Campo, Tocantinópolis, v. 3, n. 4, p. 1221-1248, 23 dez. 2018.

JADEJISKI, Rainei Rodrigues. A constituição da EEEFM Pastor Antônio Nunes de Carvalho no município de Alto Rio Novo/ES (1986-2017): um enfoque no enfrentamento da repetência e evasão escolar no Ensino Médio. 2018. 51 f. Trabalho de Conclusão de Curso (Licenciatura em Educação do Campo), Universidade Federal do Espírito Santo, Vitória, 2018.

JADEJISKI, Rainei Rodrigues; LUIZ, Miriã Lúcia. A constituição da Escola Estadual de Ensino Fundamental e Médio Pastor Antônio Nunes de Carvalho no município de Alto Rio Novo/ES (1986-2017). Revista de história e historiografia da educação, Curitiba, v. 4, n. 10, 2020.

ROCHA, Isabel Xavier de Oliveira. Uma reflexão sobre a formação integral nas EFAs: Contributos do Caderno da Realidade nesse processo na EFA de Riacho de Santana/Bahia. 2003. 242 f. Dissertação. (Mestrado Internacional em Ciências da Educação). Universidade François Rabelais de Tours - França. 2003.

ZAMBERLAN, Sérgio. Entrevista concedida a Janinha Gerke. Anchieta/ES, 7 de ago. de 2019.

\section{Sobre os Autores}

\section{Janinha Gerke}

professorajaninhaufes@gmail.com

Graduada em Pedagogia. Doutora em Educação. Professora adjunta da Universidade Federal do Espírito Santo, Departamento de Educação, Política e Sociedade, Licenciatura em Educação do Campo. Membro do Grupo de Investigação Internacional do Sistema Dual-Alternância, Universidade de Sherbrooke, Canadá e do grupo de Pesquisa CNPq Culturas, Parcerias e Educação do Campo. Autora dos livros: "Formação e Profissão Docente do Campo"; "Formação de Professores na Pedagogia da Alternância: Saberes e Fazeres do Campo".

\section{Alessandro da Silva Guimarães} alessandro2210@gmail.com

Graduado em Ciências sociais e filosofia. Mestre e doutor em Educação. Professor adjunto do departamento de Educação, Política e sociedade, atuando no curso de licenciatura em educação do campo da Universidade Federal do Espírito Santo. Coordenador do grupo de pesquisa "Os processos formativos dos estudantes do curso de Licenciatura em Educação do Campo/Ufes: um olhar com e pelos Cadernos da Realidade". 


\section{Miriã Lúcia Luiz}

miria.luiz@gmail.com

Possui graduação em Pedagogia (2004) e História (2009), mestrado (2010) e doutorado (2015) em Educação pela Universidade Federal do Espírito Santo. É professora adjunta C da Universidade Federal do Espírito Santo (UFES). É membro do Núcleo Capixaba de Pesquisa em História da Educação (NUCAPHE). 